Article

\title{
Improving the Adhesiveness of Cemented Glass Components by DBD Plasma Pre-Treatment at Atmospheric Pressure
}

\author{
Christoph Gerhard ${ }^{1, * \mathbb{D}}$, Gerrit Mielke ${ }^{1}$, Stephan Brückner ${ }^{1}$ and Olaf Wermann ${ }^{2}$ \\ 1 Faculty of Natural Sciences and Technology, University of Applied Sciences and Arts, Von-Ossietzky-Straße \\ 99, 37085 Göttingen, Germany; gerrit.mielke@hawk.de (G.M.); stephan.brueckner3@hawk.de (S.B.); \\ 2 Timotec Automatisierungstechnik GmbH, Industriepark 19, 56291 Wiebelsheim, Germany; \\ wermann@timotec.de \\ * Correspondence: christoph.gerhard@hawk.de; Tel.: +49-3375-508-220
}

Received: 25 October 2019; Accepted: 12 December 2019; Published: 14 December 2019

\begin{abstract}
Cemented optical components and groups are essential devices for the realisation of modern systems and apparatuses used in a broad range of different applications such as telecommunications, imaging and even surgery. However, various parameters may affect the stability of cemented connections. In this context, the impact of dielectric barrier discharge plasma at atmospheric pressure on the adhesiveness of cemented glass components was evaluated in the present work. For this purpose, the plasma-induced change in surface wettability and energy as well as the cement's adhesive pull strength was measured. Investigations were performed on samples, which were subject to different procedures of artificial ageing. It is shown that the adhesive pull strength of cemented glass components was notably increased after a short-term plasma treatment of merely $10 \mathrm{~s}$ due to an enhanced wettability of the applied UV-curing optical cement. The pull strength, i.e., the adhesiveness of cemented glasses was increased by a factor of 2.1 to 4.6, depending on the particularly applied artificial ageing procedure. The results and findings finally demonstrate the high potential of the applied short-term plasma treatment as a cleaning and surface activation step in optics manufacturing on an industrial scale.
\end{abstract}

Keywords: Adhesiveness; glasses; glass surfaces; surface energy; cementing; plasma treatment; optics manufacturing; assembly

\section{Introduction}

Since the realisation of the first cemented doublets in the mid-19th century, optical cements have played a key role for the manufacture of optical systems and instruments. Nowadays, classical resins and modern UV-curable cements are used for realising a variety of bonded optical components such as aplanatic, achromatic or apochromatic lenses [1-5]. Further, such optical cements are used for connecting optical communications devices, i.e., fibres and waveguides [6,7], for mounting optics [8,9] and for photonic packaging [10].

However, a number of influencing parameters and effects can contribute to a possible failure of cemented glass bonds as summarised in [11]. These include cleaning and testing procedures, the properties and surface state of the optical components, the quality and type of cement, the environmental conditions during cementing and the cementing and curing process. For instance, it is known that inhomogeneous curing due to inhomogeneous illumination by UV-light may lead to delamination and adhesive failure as a result of shaded, non-cured areas [10]. Another reason for adhesive failure is permanent mechanical shear stress within the cement layer and at its interfaces 
that arises from different indices of thermal expansion of the involved optical media [12]. Moreover, moisture and the accompanying penetration of hydrogen into cements may cause decementing [13] and, furthermore, dissolved oxygen is known to cause failure of cement films [14].

In order to overcome the problem of delaminating cementations, different alternative techniques were developed in the past. Apart from laser welding [15-17], optical contact bonding allows the long-term connection of two optical components by contacting without any additional cement [18]. In this case, bonding occurs on the basis of pure physical and intermolecular adhesion that arises as long as the form deviation between both components is smaller than one nanometre $[19,20]$. The strength of such connection can furthermore be improved by the additional application of sol gel nanoparticles [21] or the approach of activated covalent bonding where hydroxyl groups are attached on the glass surfaces prior to contacting $[22,23]$.

In any case, several material-specific characteristics and properties of the involved glasses and used cements have to be taken into account in order to realise a stable and long-term connection of optical components. One particular point is surface contamination, which may cause a failure of cemented bonds. Such contamination can even occur in the form of residues from operating materials used in classical optics manufacturing such as polishing or cleaning agents [24,25]. Especially surface-adherent water or hydrogenous compounds are precursors for failure of natural cements such as Canada balsam. Against this background, tempering is applied prior to cementing [26]. Another approach for cleaning surfaces to be cemented is the use of technical plasmas. For example, this method has a number of potential applications in medicine and dentistry [27] as well as in optics and laser technology [28,29].

Plasmas are not only very efficient in terms of precision cleaning, but also well-established for surface activation by hydrophilisation or hydrophobisation via the plasma-induced attachment of functional groups or monolayers [30,31]. As a result, the adhesiveness of glues or lacquers can be improved significantly [32]. This fact turns out to be an advantageous feature for the cementing of glasses since in this context one important aspect is the glass surface energy and its polarity, respectively. Depending on the surface tension and polarity of the used cement, replacing polar groups by non-polar, dispersive ones-and vice versa-allows improving the interlocking mechanisms between the glass surface and the cement [26]. Against this background, the impact of plasma pre-treatment on the adhesiveness of cemented glass components was evaluated in the present work where a dielectric barrier discharge plasma, i.e., a so-called "cold" plasma was applied.

\section{Experimental Setup and Procedure}

\subsection{Sample Preparation}

For the investigation of the impact of plasma pre-treatment on the adhesiveness of cemented glass components plane samples made of float glass with a diameter of $15 \mathrm{~mm}$ were used. In total, 10 samples were prepared in order to realise 5 cemented doublets. The samples were cleaned classically using ethanol and lens-cleaning paper. After such cleaning, the samples were plasma treated as described in more detail in Section 2.2. Subsequently, two samples were cemented to a doublet using a commercial UV-curable optical adhesive photopolymer (Norland Optical Adhesive NOA63, Norland Products Inc.). This adhesive is especially designed for the cementation of optical components made of glass. As usually performed in optics manufacturing, cementing was performed manually at room temperature by applying a drop of cement—with a constant volume for all samples-to the surface of one part and subsequent contacting and pressing of the other part at a constant contact pressure. Final curing of the cement was then carried out by storing the doublets in an UV-oven for $60 \mathrm{~min}$. After the actual cementing procedure, three different kinds of storing were applied as specified in detail in Table 1. 
Table 1. Overview on the different kinds of storing of cemented samples

\begin{tabular}{ll}
\hline Sample Denomination & Sample Preparation \\
\hline No ageing & Storing at ambient temperature for $48 \mathrm{~h}$ \\
\hline & Storing at ambient temperature for $48 \mathrm{~h}$, then: \\
& $\rightarrow$ tempering at a temperature of $60^{\circ} \mathrm{C}$ for $1 \mathrm{~h}$ \\
& $\rightarrow$ removal from oven \\
& $\rightarrow$ cooling down to ambient temperature \\
& $($ procedure was repeated 5 times in total) \\
\hline & Storing at ambient temperature for $48 \mathrm{~h}$, then: \\
& $\rightarrow$ placing in a water bath at room temperature \\
& $\rightarrow$ heating of water up to $65^{\circ} \mathrm{C}$ \\
& $\rightarrow$ cooling down to room temperature \\
& $\rightarrow$ removal from water bath \\
& $($ procedure was repeated 5 times in total) \\
\hline
\end{tabular}

After storing, the adhesive pull strength (APS) of cemented samples was determined by the direct pull method as defined in [33] using an APS tester (PosiTest AT-A, DeFelsko Corp.). In order to evaluate the impact of plasma pre-treatment, such measurements were performed at samples with and without plasma pre-treatment where the non-treated reference samples were also stored as specified in Table 1.

\subsection{Plasma Pre-Treatment}

For plasma pre-treatment, both surfaces to be cemented were exposed to a direct dielectric barrier discharge (D-DBD) plasma prior to cementing. Here, the investigated glass samples were placed between the electrodes of the plasma source and thus acted as dielectric barrier. The setup used for such pre-treatment is shown schematically in Figure 1.

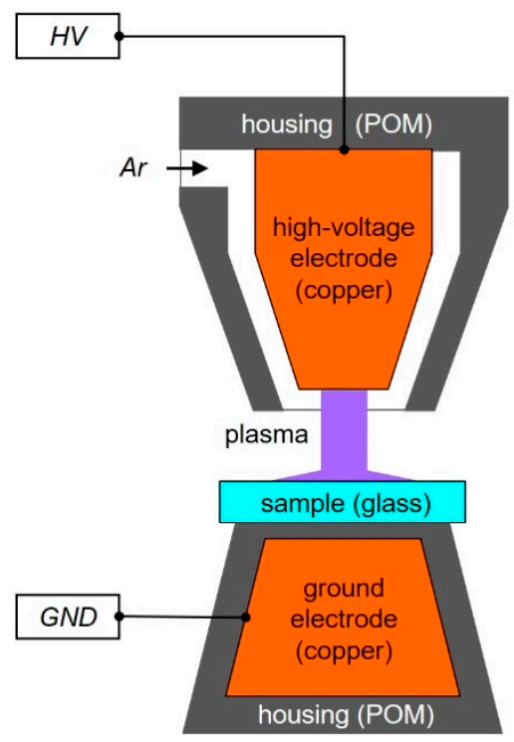

Figure 1. Schematic of the experimental setup used for direct dielectric barrier discharge (D-DBD) plasma treatment of glass surfaces to be cemented.

In comparison to atmospheric pressure plasma jets or torches, this type of plasma stands out due to different advantageous features: First, the plasma is ignited directly on the surface of interest (see Figure 1), i.e., the surface to be cemented in the present case. The plasma species required for initiating surface reactions are thus generated close to the area of treatment. Second, plasma-induced ultraviolet irradiation, which is normally absorbed by the surrounding atmosphere, can contribute to plasma-chemical near-surface mechanisms such as the decomposition of surface-adherent molecules. 
Third, the direct ignition on the sample surface results in the formation of high electric field strengths at the surface and particularly at roughness peaks, leading to an acceleration of charge carriers towards the surface. This mechanism allows a certain selective material removal and a fine polishing of the glass surface [34,35]. Finally, electric current between the two involved electrodes is significantly limited because the glass sample itself acts as dielectric barrier. A D-DBD thus features comparatively low gas temperatures. In the setup used here, the maximum temperature heating of the glass surface amounts to approximately $T_{\max }=90^{\circ} \mathrm{C}$ as determined in previous work [36], i.e., well below the softening point of optical glasses.

The plasma source was driven by a pulsed power supply providing alternating sinusoidal high-voltage pulses with a repetition rate of $f=7 \mathrm{kHz}$. The voltage and duration of each pulse was $U=11 \mathrm{kV}$ and $\tau=80 \mu \mathrm{s}$, respectively, see Figure 2. As a result, the energy of each high-voltage pulse accounted for $E=0.17 \mathrm{~mJ}$ and the averaged power dissipated in the plasma was $P=1.19 \mathrm{~W}$ as determined using the Lissajous method [37]. This method is an appropriate means for the determination of the dissipated pulse energy, since the voltage, as well as the current, have high rates of change with an uncertain phase position.
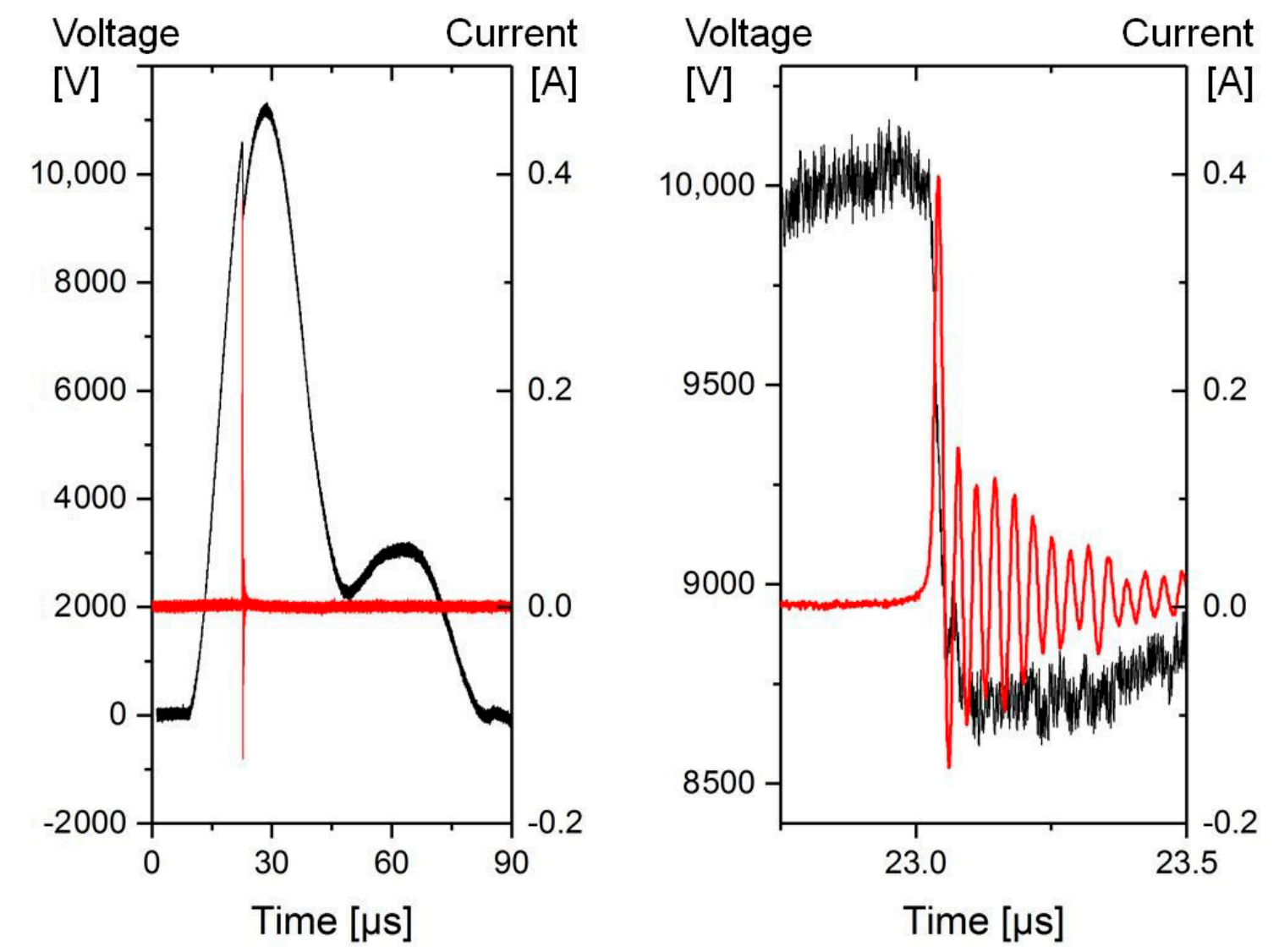

Figure 2. Depiction of the applied voltage pulse shape (black) and the resulting current impulse (red) on the example of the positive pulse. Here, the formation of the plasma occurs on the rising edge of the voltage pulse, leading to a short-term voltage drop and a quick increase of the discharge current.

Prior to cementing, plasma treatment of the glass sample surfaces was performed for in total $10 \mathrm{~s}$ ( $5 \mathrm{~s}$ per surface) where the plasma process gas was argon at a flow rate of 4 standard litres per minute (slm). Such short treatment duration was chosen since the major fraction of a plasma-induced change in contact angle on glass surfaces is achieved after merely some seconds [38]. The treatment was performed in a static arrangement. This means that the glass samples were placed in the centre of the plasma source (compare Figure 1). Once the plasma was ignited, its footprint covered the entire 
sample surface with a diameter of $15 \mathrm{~mm}$. Even though this static approach results in a Gaussian-like spatial distribution of the plasma over the surface, a nearly homogenous impact of the plasma was observed due to the small sample size.

Before and after plasma treatment the contact angle of both water and the used optical cement was measured with the aid of a contact angle measurement device (Contact Angle Measurement System $\mathrm{G10}$, Krüss $\mathrm{GmbH}$ ). Such measurement was performed because the contact angle of a liquid on a test surface is one of the most commonly-used indication value for cleaning processes. Since the contact angle is directly related to the surface energy, it also allows describing activation effects as for example a change in surface polarity [39]. Moreover, the surface energy before and after plasma treatment was determined according to the Owens-Wendt-Rabel-Kaelble (OWRK) method as described in detail in $[40,41]$.

\section{Results and Discussion}

It is well known that atmospheric pressure plasmas are efficient tools for cleaning glass surfaces by the removal of organic contaminations as demonstrated by various authors in the past [24,42-45]. The high potential of this technique was also observed in the present case. As shown in Figure 3, even persistent fingermarks can be removed from polished lens surfaces. Here, a quite long-term plasma treatment as described in Section 2.2 was performed for $5 \mathrm{~min}$ in order to visualise its remarkable impact on such severe surface contamination.

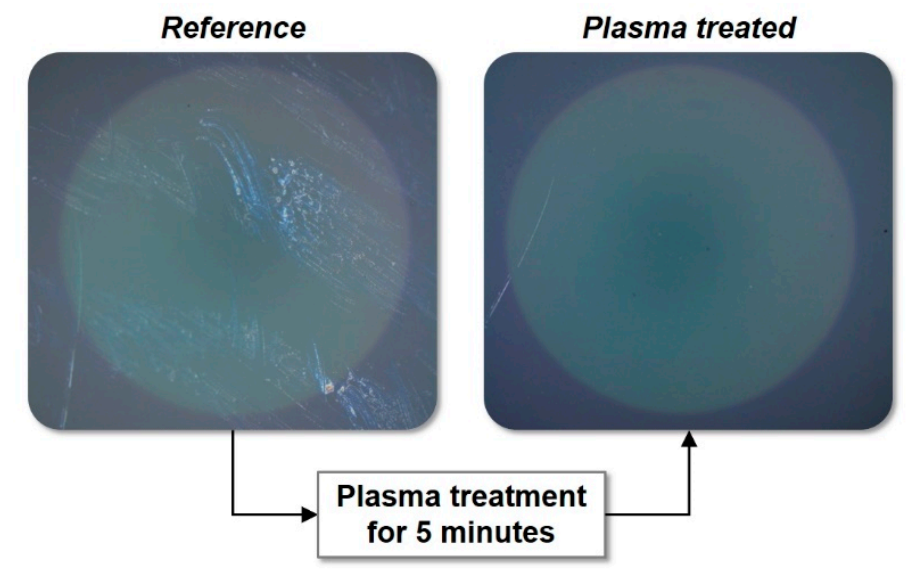

Figure 3. Visualisation of the impact of plasma treatment on a polished lens surface with fingermarks (light microscopic image, magnification 20x); left: before plasma treatment, right: after plasma treatment for $5 \mathrm{~min}$.

The effect of plasma-induced cleaning is due to several interacting plasma-chemical and plasma-physical mechanisms. First, the presence of surrounding air allows a chemical cleaning by the decomposition of surface-adherent hydrocarbons. In an atmospheric pressure plasma operated as in the present case, surrounding air is ingested and mixes with the actual plasma process gas, argon, which thus practically acts as carrier gas. Subsequently, molecular oxygen is dissociated to atomic oxygen (e.g., by electron impact-induced dissociation) as observed via plasma emission spectroscopy. Due to the discharge geometry, this occurs close to the sample surface. Once atomic hydrogen gets in contact with surface contaminants, it is capable of decomposing hydrocarbons to gaseous, volatile carbon dioxide and water. Here, an intermediate species, ozone $\left(\mathrm{O}_{3}\right)$, is also of essential importance. Another process can also induce such decomposition: The high-energetic UV-irradiation, which is emitted by the plasma directly on the sample surface, gives rise to a photo-fragmentation of oxygen molecules. At the same time, surface-adherent hydrocarbons are decomposed by the irradiation. The plasma species formed in that way, i.e., atomic oxygen, carbon and hydrogen as well as molecule fragments and ozone finally form volatile gaseous water and carbon dioxide. At last, pure physical 
bombardment of the surface with argon ions from the plasma may further contribute to surface cleaning by sputtering. However, the mean kinetic energy of ions in DBD plasmas is normally rather negligible as represented by the moderate gas temperature [46]. In contrast, excited state argon is capable of transferring a notable amount of energy (e.g., $11.5 \mathrm{eV}$ for metastable argon [47]) to surface-adherent contaminants. The number of such states is further considerably higher than the number of argon ions. The energy provided by de-excitation processes of excited argon states could thus represent an essential additional contribution for the cleaning process.

In any case, the observed surface cleaning is obviously due to a plasma-induced removal of hydrocarbons or other carbonaceous surface-adherent contaminants. Apart from removal, plasma is capable of modifying carbonaceous surface-adherent contaminants by altering the percentage of involved carbon-based bonds as measured via X-ray photoelectron spectroscopy (XPS) and presented in previous work [38]. Such removal or modification of carbonaceous bonds can easily be detected by a decrease in water contact angle [38]. In the present case, the water contact angle was reduced from approximately $19^{\circ}$ before plasma treatment to $<4^{\circ}$ after plasma treatment for $10 \mathrm{~s}$. This decrease corresponds to a plasma-induced increase in surface energy of the treated glass samples which directly impacts the wetting characteristics of cement applied to the glass surface as shown in Figure 4.

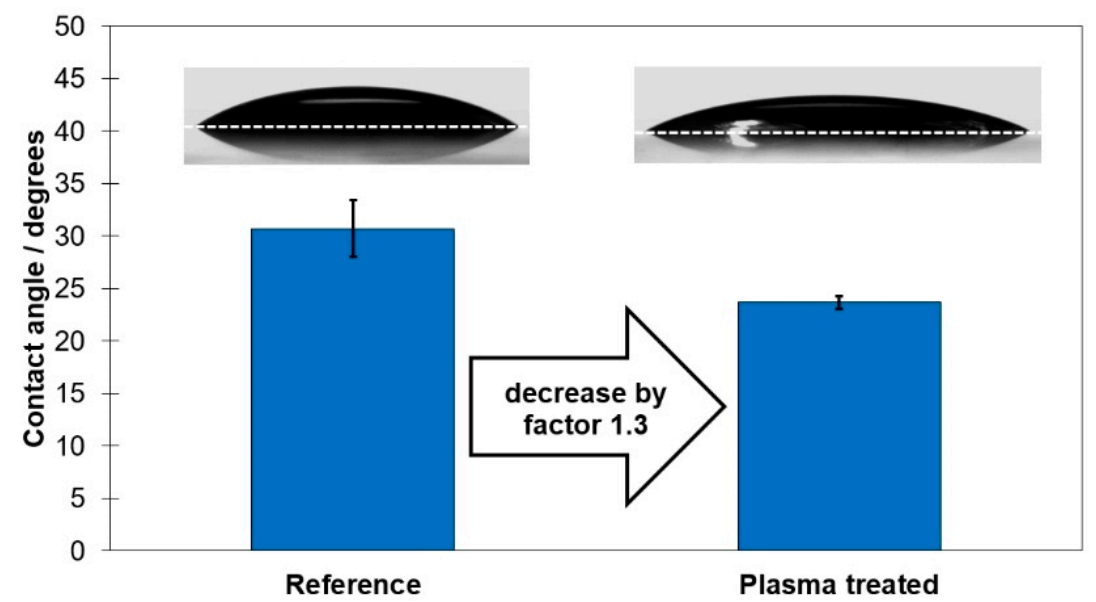

Figure 4. Impact of plasma treatment of $10 \mathrm{~s}$ on the contact angle of UV-curable optical cement (error bars represent standard deviation of five measurements).

It turns out that the contact angle of the used cement is decreased by a factor of about 1.3 (from $30.7^{\circ}$ to $23.7^{\circ}$ ) after plasma treatment for merely $10 \mathrm{~s}$. This corresponds to an improved wetting and thus an enhanced adhesion of the cement at the glass surface. Such improved adhesion characteristics of cemented glasses were also observed after curing and storing as described in detail in Table 1 . Figure 5 shows a comparison of the measured adhesive pull strengths (APS) of cemented and differently stored samples before and after plasma treatment. 


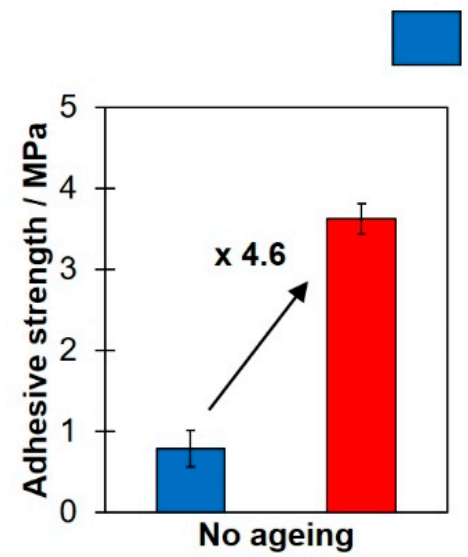

: Reference $\square$ : Plasma treated

Figure 5. Comparison of the particular adhesive pull strengths of non-treated reference and plasma treated (for $10 \mathrm{~s}$ ) samples after different storing procedures as described in detail in Table 1 (error bars represent standard deviation of five measurements).

It can be seen that for the samples without any artificial ageing, the APS was significantly increased by a factor of approximately 4.6 (from $0.79 \mathrm{MPa}$ before to $3.63 \mathrm{MPa}$ after plasma treatment). This trend, i.e., an improved adhesion due to the plasma treatment, is also observed for aged samples: After pure tempering as described in Table 1, the APS of the reference samples was 1.47 MPa. This value was increased to $4.34 \mathrm{MPa}$ by the plasma treatment, corresponding to a factor of about 2.9. It thus turns out that again, the adhesion of the cement was improved whereas the initial APS value of the non-treated reference sample is notably higher in comparison to the reference samples without any storing or ageing. This also applies to the reference samples that were tempered and additionally placed in a water bath. This effect can be explained by the fact that the used cement is not only completely cured by the UV-irradiation, but needs some further relaxing time. Here, a certain heating as initially induced by tempering and heating the water bath as performed in the present case is an advantage since an increase in temperature supports the polymerisation process. However, in comparison to the samples without any ageing, the applied long-term tempering procedure results in failure of the cementation. Periodical tempering and cooling contributes to cement delamination by inducing mechanical stress due to different coefficients of thermal expansion of the glasses and the cement [12]. An additional storing in water bath further comes along with diffusion of water and hydrogen into the cement and along the cement-glass interface, leading to decementing [13]. However, even in this extreme case, which represents an extraordinary aggressive environment, plasma treatment has turned out to improve the stability of cementation. Without plasma treatment, an APS of 1.12 MPa was determined. For plasma treated samples, the APS was $2.31 \mathrm{MPa}$, ending up in a factor of approximately 2.1.

The observed increase in APS in all cases can mainly be attributed to the plasma-induced improvement in wettability and adhesiveness of the cement on the glass surfaces. Such improvement is due to two major effects: First, surface cleaning and second, surface activation by attaching functional groups and an accompanying change in surface energy. It is known from literature that the surface tension of the used liquid cement before curing should be significantly smaller than the surface energy of the substrate, i.e., the glass surface [48]. As an estimation, the difference should at least amount to $10 \mathrm{mN} / \mathrm{m}$. In the present case, a surface tension of the liquid cement of $45.96 \mathrm{mN} / \mathrm{m}$ was determined experimentally. The surface tension of the investigated glass was $56.22 \mathrm{mN} / \mathrm{m}$ before and $78.81 \mathrm{~N}$ $\mathrm{mN} / \mathrm{m}$ after plasma treatment. Hence, the treatment increased the difference in surface energy from $10.26 \mathrm{mN} / \mathrm{m}$ (which is nearly the above-mentioned minimum value) to $32.85 \mathrm{mN} / \mathrm{m}$. This corresponds to an increase in difference by a factor of approximately 3 , explaining and confirming the notable plasma-induced enhancement of the cemented bond as described above. 


\section{Conclusions}

The results presented in this contribution clearly show the positive impact of the applied plasma treatment on the adhesiveness of UV-curing optical cement on polished glass surfaces. One has to notice that an improved stability up to a factor of about 4.6 as expressed by the adhesive pull strength was achieved after merely $10 \mathrm{~s}$ of plasma treatment. Such short-term process (for comparison, the polishing process takes approximately six hours) is thus of interest for precision cleaning of optics surfaces on an industrial scale. This approach could thus be integrated in existing production chains as an additional step prior to cementing after further preparatory work for technology transfer. For instance, the impact of scanning and rotation of the plasma source over the surface of larger optics surfaces on the homogeneity of plasma treatment and the resulting increase in adhesiveness should be investigated. Moreover, variations in thickness of an optical component lead to a change in discharge gap and plasma properties and composition, respectively. Such variations could be addressed and compensated by a dynamic adjustment of the output parameters of the used plasma power supply and the distance between the two involved electrodes.

Moreover, plasma treatment does not only allow an enhanced cementation of optically active surfaces. It is also suitable as a preparation step for mounting processes of opto-mechanical systems. Here, optical elements are often fixed on mechanical holders or in lens mounts using two-component glues [5]. An improved wetting of such glues on polished glass surfaces was also observed in the course of comparative experiments in the present work. Here, a plasma-induced reduction in contact angle by a factor of approximately 1.6 (from $50.54^{\circ}$ to $32.12^{\circ}$ ) was measured. It can thus finally be stated that-considering the advantage of a simple integration and the low gas temperature-dielectric barrier discharge plasmas at atmospheric pressure have a high potential in optics manufacturing and especially in surface cleaning and activation for improving the long-term stability of cemented and glued connections. Based on the findings of the present work it can moreover be assumed that the applied plasma treatment may also improve the stability and adhesiveness of dielectric and metallic coatings. This aspect will be investigated in ongoing work.

Author Contributions: C.G. acquired the funding and administrated the project, conceived and designed the experiments, analysed the data, visualised the obtained data, wrote the original draft, and reviewed and edited the final paper draft; G.M. prepared the samples, performed the experiments, analysed the data, and reviewed and edited the paper draft; S.B. supervised the experiments, validated the obtained results, and reviewed and edited the paper draft; O.W. acquired the funding and administrated the project, conceived experiments, and reviewed and edited the paper draft.

Funding: This work was funded by the Federal Ministry for Economic Affairs and Energy (Bundesministerium für Wirtschaft und Energie, BMWi) in the frame of the SME Central Innovation Programme (Zentrales Innovationsprogramm Mittelstand, ZIM), project "Atmospheric pressure plasma finishing of optical components" ("Atmosphärendruckplasma-Finishing optischer Komponenten", AtmoKo), grant no. ZF 4047502DF5.

Acknowledgments: The authors thank Julia Stachowiak and Daniel Tasche for their help during experimentation.

Conflicts of Interest: The authors declare no conflict of interest. At the time of experimentation, the authors C.G. and S.B. worked at the IST Fraunhofer Institute for Surface Engineering and Thin Films, Application Center for Plasma and Photonic in Göttingen, Germany. The funders had no role in the design of the study; in the collection, analyses, or interpretation of data; in the writing of the manuscript, or in the decision to publish the results.

\section{References}

1. Dreyfus, M.G.; Bishop, R.E.; Moorhead, J.E. Aplanatic cemented doublet design. J. Opt. Soc. Am. 1960, 50, 375-378. [CrossRef]

2. Shields, J. Adhesives in instrumentation. J. Phys. E Sci. Instrum. 1972, 5, 109-116. [CrossRef]

3. Iqbal Khan, M.; MacDonald, J. Cemented doublets - a method for rapid design. Opt. Acta 1982, 29, 807-822. [CrossRef]

4. Beamonte, J.I. Stability of the spherical aberration up to the fifth order in cemented doublets. J. Opt. A-Pure Appl. Opt. 2000, 2, 161-168. [CrossRef] 
5. Gerhard, C. Optics Manufacturing: Components and Systems, 1st ed.; CRC Taylor \& Francis: Boca Raton, FL, USA, 2017; pp. 179-188.

6. Murata, N.; Nakamura, K. UV-curable adhesives for optical communications. J. Adhes. 1991, 35, $251-267$. [CrossRef]

7. Nagata, N.; Shiroishi, M.; Miyama, Y.; Mitsugi, N.; Miyamoto, N. Evaluation of new UV-curable adhesive material for stable bonding between optical fibers and waveguide devices: Problems in device packaging. Opt. Fiber Technol. 1995, 1, 283-288. [CrossRef]

8. Carnell, K.H.; Kidger, M.J.; Overill, A.J.; Reader, R.W.; Reavell, F.C.; Welford, W.T.; Wynne, C.G. Some experiments on precision lens centring and mounting. Opt. Acta 1974, 21, 615-629. [CrossRef]

9. Hopkins, R.E. Some thoughts on lens mounting. Opt. Eng. 1976, 15, 428-430. [CrossRef]

10. Uddin, M.A.; Chan, H.P.; Lam, K.W.; Chan, Y.C.; Chu, P.L.; Hung, K.C.; Tsun, T.O. Delamination problems of UV-cured adhesive bonded optical fiber in V-groove for photonic packaging. IEEE Photonic. Tech. Lett. 2004, 16, 1113-1115. [CrossRef]

11. Woods, H.F. Causes for separation in U.V. adhesive bonded optical assemblies. In Proceedings of the SPIE's 1993 International Symposium on Optics, Imaging, and Instrumentation (Proc. of SPIE 1999 - Adhesives Engineering), San Diego, CA, USA, 11-16 June 1993; Norland, E.A., Liechti, K.M., Eds.; pp. 59-62.

12. Yoder, P.R.; Vukobratovich, D. Shear stresses in cemented and bonded optics due to temperature changes. In Proceedings of the SPIE 9573 - Optomechanical Engineering, San Diego, CA, USA, 9-13 August 2015; Hatheway, A.E., Ed.;

13. Brockmann, W.; Geiß, P.L.; Klingen, J.; Schröder, K.B. Adhesive Bonding: Materials, Applications and Technology, 1st ed.; John Wiley \& Sons: Hoboken, NJ, USA, 2008; pp. 314-315.

14. Twymann, F. Prism and Lens Making, 2nd ed.; Adam Hilger: Bristol, UK; New York, NY, USA, 1952; pp. 66-118.

15. Tamaki, T.; Watanabe, W.; Itoh, K. Laser micro-welding of transparent materials by a localized heat accumulation effect using a femtosecond fiber laser at $1558 \mathrm{~nm}$. Opt. Express 2006, 14, 10460-10468. [CrossRef]

16. Richter, S.; Döring, S.; Tünnermann, A.; Nolte, S. Bonding of glass with femtosecond laser pulses at high repetition rates. Appl. Phys. A 2011, 103, 257-261. [CrossRef]

17. Hélie, D.; Bégin, M.; Lacroix, F.; Vallée, R. Reinforced direct bonding of optical materials by femtosecond laser welding. Appl. Opt. 2012, 51, 2098-2106. [CrossRef] [PubMed]

18. Haisma, J.; Spierings, G.A.C.M. Contact bonding, including direct-bonding in a historical and recent context of materials science and technology, physics and chemistry: Historical review in a broader scope and comparative outlook. Mater. Sci. Eng. R Rep. 2002, 37, 1-60. [CrossRef]

19. Smith, H.H. Optical-contact bonding. J. Acoust. Soc. Am. 1965, 37, 928-929. [CrossRef]

20. Greco, V.; Marchesini, F.; Molesini, G. Optical contact and van der Waals interactions: The role of the surface topography in determining the bonding strength of thick glass plates. J. Opt. A-Pure Appl. Opt. 2001, 3, 85-88. [CrossRef]

21. Sivasankar, S.; Chu, S. Optical bonding using silica nanoparticle sol-gel chemistry. Nano Lett. 2007, 7, 3031-3034. [CrossRef]

22. Kalkowski, G.; Risse, S.; Rothhardt, C.; Rohde, M.; Eberhardt, R. Optical contacting of low-expansion materials. In Proceedings of the SPIE 8126-Optical Manufacturing and Testing IX, San Diego, CA, USA, 21-25 August 2011; 81261F (7p).

23. Turner, T.; Casnedi, P. Novel bonding technology improves optical assemblies. EuroPhotonics 2013, 2013, $27-29$.

24. Gerhard, C.; Weihs, T.; Tasche, D.; Brückner, S.; Wieneke, S.; Viöl, W. Atmospheric pressure plasma treatment of fused silica, related surface and near-surface effects and applications. Plasma Chem. Plasma Process. 2013, 33, 895-905. [CrossRef]

25. Gerhard, C.; Tasche, D.; Uteza, O.; Hermann, J. Investigation of nonuniform surface properties of classically-manufactured fused silica windows. Appl. Opt. 2017, 56, 7427-7434. [CrossRef]

26. Hunt, P.G. Optical cements - a laboratory assessment. Opt. Acta 1967, 14, 401-435. [CrossRef]

27. Liu, T.; Hong, L.; Hottel, T.; Dong, X.; Yu, Q.; Chen, M. Non-thermal plasma enhanced bonding of resin cement to zirconia ceramic. Clin. Plasma Med. 2016, 4, 50-55. [CrossRef] [PubMed] 
28. Gerhard, C.; Tasche, D.; Munser, N.; Dyck, H. Increase in nanosecond laser-induced damage threshold of sapphire windows by means of direct dielectric barrier discharge plasma treatment. Opt. Lett. 2017, 42, 49-52. [CrossRef] [PubMed]

29. Gerhard, C.; Stappenbeck, M. Impact of the polishing suspension concentration on laser damage of classically-manufactured and plasma post-processed zinc crown glass surfaces. Appl. Sci. 2018, 8, 1556. [CrossRef]

30. Yamamoto, T.; Okubo, M.; Imai, N.; Mori, Y. Improvement on hydrophilic and hydrophobic properties of glass surface treated by nonthermal plasma induced by silent corona discharge. Plasma Chem. Plasma Process. 2004, 24, 1-12. [CrossRef]

31. Cheruthazhekatt, S.; Černák, M.; Slavíček, P.; Havel, J. Gas plasmas and plasma modified materials in medicine. J. Appl. Biomed. 2010, 8, 55-66. [CrossRef]

32. Bellmann, M.; Gerhard, C.; Haese, C.; Wieneke, S.; Viöl, W. DBD plasma improved spot repair of automotive polymer surfaces. Surf. Eng. 2012, 28, 754-758. [CrossRef]

33. Jacobssen, R.; Kruse, B. Measurement of adhesion of thin evaporated films on glass substrates by means of the direct pull method. Thin Solid Films 1973, 15, 71-77. [CrossRef]

34. Gerhard, C.; Roux, S.; Brückner, S.; Wieneke, S.; Viöl, W. Low-temperature atmospheric pressure argon plasma treatment and hybrid laser-plasma ablation of barite crown and heavy flint glass. Appl. Opt. 2012, 51, 3847-3852. [CrossRef]

35. Gerhard, C.; Weihs, T.; Luca, A.; Wieneke, S.; Viöl, W. Polishing of optical media by dielectric barrier discharge inert gas plasma at atmospheric pressure. J. Eur. Opt. Soc. Rapid Publ. 2013, 8, 13081. [CrossRef]

36. Gredner, A.; Gerhard, C.; Wieneke, S.; Schmidt, K.; Viöl, W. Increase in generation of poly-crystalline silicon by atmospheric pressure plasma-assisted excimer laser annealing. J. Mater. Sci. Eng. B 2013, 3, 346-351.

37. Helmke, A.; Hoffmeister, D.; Mertens, N.; Emmert, S.; Schuette, J.; Viöl, W. The acidification of lipid film surfaces by non-thermal DBD at atmospheric pressure in air. New, J. Phys. 2009, 11, 115025. [CrossRef]

38. Gerhard, C.; ten Bosch, L. Plasma jet cleaning of optics-Cleaning of silver-coated mirrors by means of atmospheric pressure plasma jets. Vakuum in Forschung und Praxis 2018, 30, 32-35. [CrossRef]

39. Homola, T.; Matoušek, J.; Kormunda, M.; Wu, L.Y.L.; Černák, M. Plasma treatment of glass surfaces using diffuse coplanar surface barrier discharge in ambient air. Plasma Chem. Plasma, Process. 2013, 33, 881-894. [CrossRef]

40. Owens, D.K.; Wendt, R.C. Estimation of the surface free energy of polymers. J. Appl. Polym. Sci. 1969, 13, 1741-1747. [CrossRef]

41. Kaelble, D.H. Dispersion-polar surface tension properties of organic solids. J. Adhesion 1970, 2, 66-81. [CrossRef]

42. Shun'ko, E.V.; Belkin, V.S. Cleaning properties of atomic oxygen excited to metastable state $2 s^{2} 2 p^{4}\left({ }^{1} \mathrm{~S} 0\right)$. J. Appl. Phys. 2007, 102, 083304. [CrossRef]

43. Iwasaki, M.; Inui, H.; Matsudaira, Y.; Kano, H.; Yoshida, N.; Ito, M.; Hori, M. Nonequilibrium atmospheric pressure plasma with ultrahigh electron density and high performance for glass surface cleaning. Appl. Phys. Lett. 2008, 92, 081503. [CrossRef]

44. Iwasaki, M.; Matsudaira, Y.; Takeda, K.; Ito, M.; Miyamoto, E.; Yara, T.; Uehara, T.; Hori, M. Roles of oxidizing species in a nonequilibrium atmospheric-pressure pulsed remote $\mathrm{O}_{2} / \mathrm{N}_{2}$ plasma glass cleaning process. J. Appl. Phys. 2008, 103, 023303. [CrossRef]

45. Buček, A.; Homola, T.; Aranyosiová, M.; Velič, D.; Plecenik, T.; Havel, J.; St'ahel, P.; Zahoranová, A. Atmospheric pressure nonequilibrium plasma treatment of glass surface. Chem. Listy 2008, 102, S1459-S1462.

46. Hoffmeister, J.; Brückner, S.; Gerhard, C.; Wieneke, S.; Viöl, W. Impact of the thermal lens effect in atmospheric pressure DBD-plasma columns on coaxially guided laser beams. Plasma Sources Sci. Technol. 2014, 23, 064008. [CrossRef]

47. Bogaerts, A.; Gijbels, R. Comparison of argon and neon as discharge gases in a direct-current glow discharge a mathematical simulation. Spectrochim. Acta B 1997, 52, 553-565. [CrossRef]

48. Magyar, J.T. History of and potential for optical bonding agents in the visible. In Proceedings of the SPIE 1535 - Passive Materials for Optical Elements, San Diego, CA, USA, 21 July 1991; Wilkerson, G.W., Ed.; pp. 55-58. 